\title{
A technique for accurate energy yields prediction of photovoltaic system
}

\author{
Chiou-Jye Huang ${ }^{a^{*}}$, Chao-Yang Huang ${ }^{\mathrm{a}, \mathrm{b}}$, Po-Chun Huang ${ }^{\mathrm{a}}$, Shun-Hung Tsai ${ }^{\mathrm{c}}$ \\ ${ }^{a}$ Green Energy \& Environment Research Laboratories, Industrial Technology Research Institute, Hsinchu, Taiwan \\ ${ }^{b}$ Department of mechanical engineering, National Chiao Tung University, Hsinchu, Taiwan \\ ${ }^{c}$ Institute of Automation Technology, National Taipei University of Technology, Taipei, Taiwan
}

\begin{abstract}
In this paper, the authors have investigated the long-term energy prediction of photovoltaic system in Hsinchu Taiwan. The steady-state model of the photovoltaic system has been used. The evaluation for energy prediction of the photovoltaic system has been developed with the integration of photovoltaic modules temperature losses. PV energy generation prediction employs module performance, installation site and meteorological data information. A simple model is created to simulate the energy yields of using PV module thermal model. PV module thermal model is created for the module temperature, ambient temperature and solar radiation. In this present study, the prediction model is created to simulate the energy yields of PV system. Experimental results show that our energy yields prediction results of PV system have clearly demonstrated that the root-meat-squared error (RMSE) performance is very well. The yearly RMSE of our prediction model is $4.92 \%$ better than PVSYS 5.42 model.
\end{abstract}

Keywords: Energy prediction, photovoltaic system, energy yields

\section{Introduction}

In the past decades, large-scale photovoltaic system has been spread worldwide in developed countries. The advantages of using the photovoltaic plant generated electricity, its pollution free, silent and absolutely low maintenance. Especially, the grid connected applications are represent the fastest growth of the photovoltaic market. There is an important point that the PV output affects the power system stability, which is how it can be work more accurately to predict the power output for the photovoltaic power plants, industry, and academia to forecast effectively? Forecasting the power output of photovoltaic power plant research and applications can be classified into two categories: one is based on the intensity of solar irradiation of prediction model. The solar irradiation model has being established according to the local weather history to predict the value of the solar irradiation. Finally, the PV system output can be predicted, such as [1]-[7]. The model is dependent on the detailed meteorological data. If we require more accurate forecasting results, the model should be requirement, more complex to fulfill our according to the history of the weather with more data types. It will make the prediction process to be very cumbersome and not conducive to the realization of the actual situation.

The goal of another forecasting method is to be prediction the output form the PV power stations. The PV power stations and grid connected operation of photovoltaic panels, geographical location, environment and inverter systems have been identified by historical operating data which is a reasonable statistical model predicting the PV system output power directly. It needs to eliminate a large number of the meteorological statistical process and twice complex modeling process for several times, to simplify the prediction power output process. Under varying operating conditions, the objective of this paper is to pursue a model with acceptable precision estimating the actual performance of the PV system.

\footnotetext{
* Manuscript received May 2, 2013; revised July 3, 2013.

Corresponding author. Tel.: +886-3-5912210; E-mail address: chioujye@itri.org.tw.
} 
In this paper, we develop a method to accurate energy prediction estimation of PV system based on math thermal model. In Section II, we address the PV model dynamics. Section III presents the system Mathematical Thermal Model. In Section IV we discuss simulation results. Finally, Section V provides the conclusions and discussions.

\section{The Mathematical Method to Calculate Tilt Angle of Solar Irradiance}

The solar panels should be installed with a slope and oriented toward south direction. But, it is necessary to correct the solar radiation horizontally to tilted surface [8], [9] using the following equations (1)-(4):

$$
\begin{aligned}
& H_{b t}=H_{b} R_{b} \\
& \begin{aligned}
R_{b}= & \frac{\cos \theta}{\cos \theta_{z}}
\end{aligned} \\
& \begin{aligned}
\cos \theta & =\sin \delta \sin \varphi \cos \beta-\sin \delta \cos \varphi \sin \beta \cos \gamma+\cos \delta \cos \varphi \cos \beta \cos \omega \\
& \quad+\cos \delta \sin \varphi \sin \beta \cos \omega \cos \gamma+\cos \delta \sin \beta \sin \gamma \sin \omega
\end{aligned} \\
& \delta=23.45 \sin \left(360^{\circ} \frac{(284+n)}{365}\right)
\end{aligned}
$$

where $H_{b}$ and $H_{b t}$ are presented direct radiation and ground reflected radiation on tiled surface, respectively; $R_{b}$ is defined as the ratio of daily average direct radiation. $\theta$ is solar incident angle to tiled surface, $\varphi$ is site latitude, $\gamma$ is azimuth angle of collector, $\omega$ is hour angle, and $\delta$ is declination of the sun, $n$ is the day of the year starting from the 1 st of January. The geometrical relationships between various angles are shown in the Fig. 1.

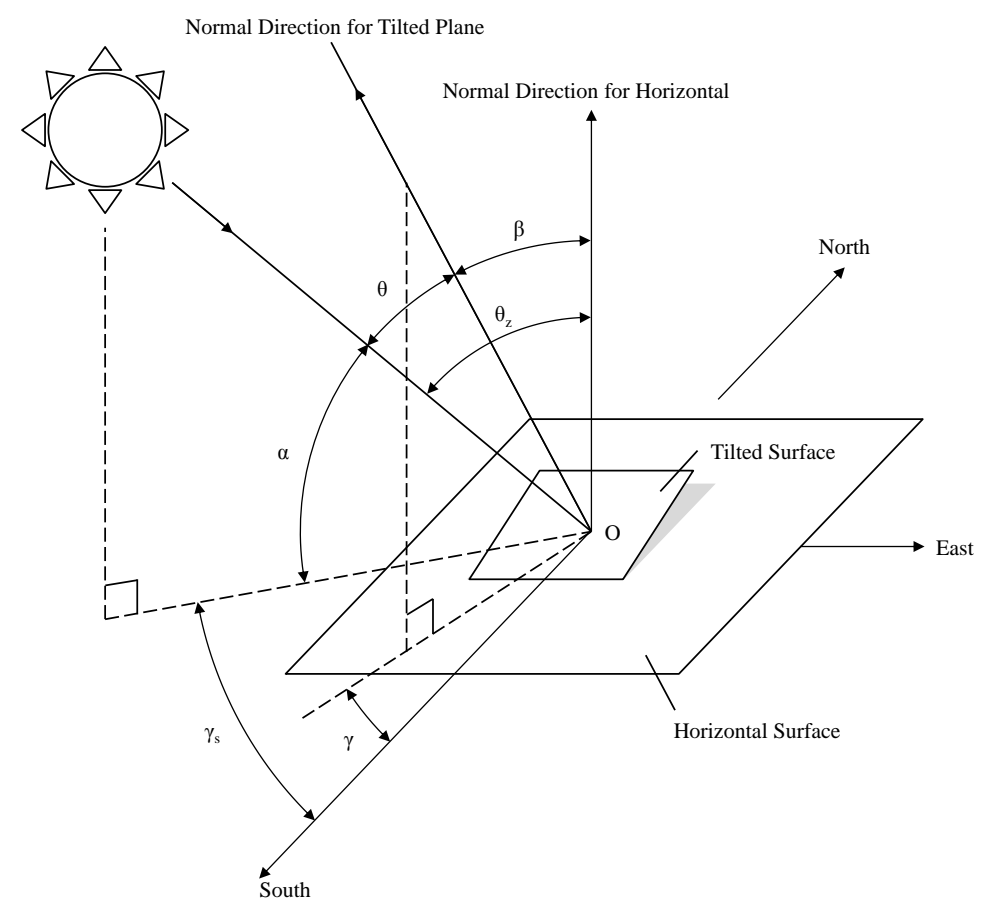

Fig. 1. Geometrical relationships between various angles. 
When the azimuth angle of collector $\gamma$ and tilted angle $\beta$ are both zero, Eq. (3), mainly the same formula to calculate solar altitude $\alpha$, is presented as follow:

$$
\cos \theta_{z}=\sin \delta \sin \varphi+\cos \delta \cos \varphi \cos \omega
$$

where $\theta_{z}$ is solar incident angle to horizontal surface.

\section{Mathematical Thermal Model of PV System}

Thermal model approach the consistence in local meteorological data including ambient temperature, wind speed and solar radiation. In this study, the International Electrotechnical Commission (IEC) was adopted [10] as the reference. For the crystalline silicon PV module, the testing procedure of NOCT is specified by IEC no. 61215 [10]. NOCT is defined as the solar cell junction temperature which is reached by open circuited cells, installed on an open rack, under the following standard reference environment (SRE) conditions [10]: (a) solar irradiance on the cell surface is $800 \mathrm{~W} / \mathrm{m}^{2}$, (b) ambient temperature is $20^{\circ} \mathrm{C}$, and (c) wind speed is $1 \mathrm{~m} / \mathrm{s}$.

The power output of the PV system depends on the incident radiation and the cell temperature [11]. The PV system power output is calculated by:

$$
\begin{aligned}
& P_{p v s}=G_{T} A_{p v s} \eta_{S T C} f \\
& f=\left[1-\beta\left(T_{c}-T_{c, S T C}\right)\right]
\end{aligned}
$$

where $P_{p v s}$ is power output for PV system, $G_{T}$ is the solar radiation on tilted surface, $A_{p v s}$ is installation area of PV system, $\eta_{S T C}$ is the PV module efficiency at standard test conditions, $f$ is the PV derating factor that shows wiring losses, shading and aging of the panels, $\beta$ is the temperature coefficient of PV module, $T_{c}$ is the PV cell temperature and $T_{c, S T C}$ is the PV cell temperature under standard test conditions, calculated according to:

$$
T_{c}=T_{a}+\frac{(N O C T-20)}{800} G_{T}
$$

PV module temperature is influent the power performance of PV modules. Under steady state conditions the electrical energy yields primarily depends on the cell temperature $T_{c}$ and where $T_{a}$ is the ambient temperature.

\section{System Performance and Discussion}

The photovoltaic system is composed of 20 PV panels and the semi-transparent c-Si PV module (see Table 1) is installed in tiled roof to replace the building material (see Fig. 2). The BIPV system is local in Industrial Technology Research Institute campus where was the $23^{\circ} 18^{\prime}$ North Latitude and $120^{\circ} 28^{\prime}$ East Longitude in Taiwan. Using the thermal model based on the energy generated prediction was investigated in this paper.

It defines the root-meat-squared error (RMSE) to determine the accuracy of the measurement and prediction results. The RMSE is as bellow:

$$
\begin{aligned}
& \text { Error }=\sum_{1}^{n} \frac{S-M}{M} 100 \% \\
& \text { RMSE }=\sqrt{\frac{1}{n} \sum_{1}^{n} \text { Error }^{2}}
\end{aligned}
$$

where $M$ is the measurement data, $S$ is the simulation data, and $n$ is the month. 

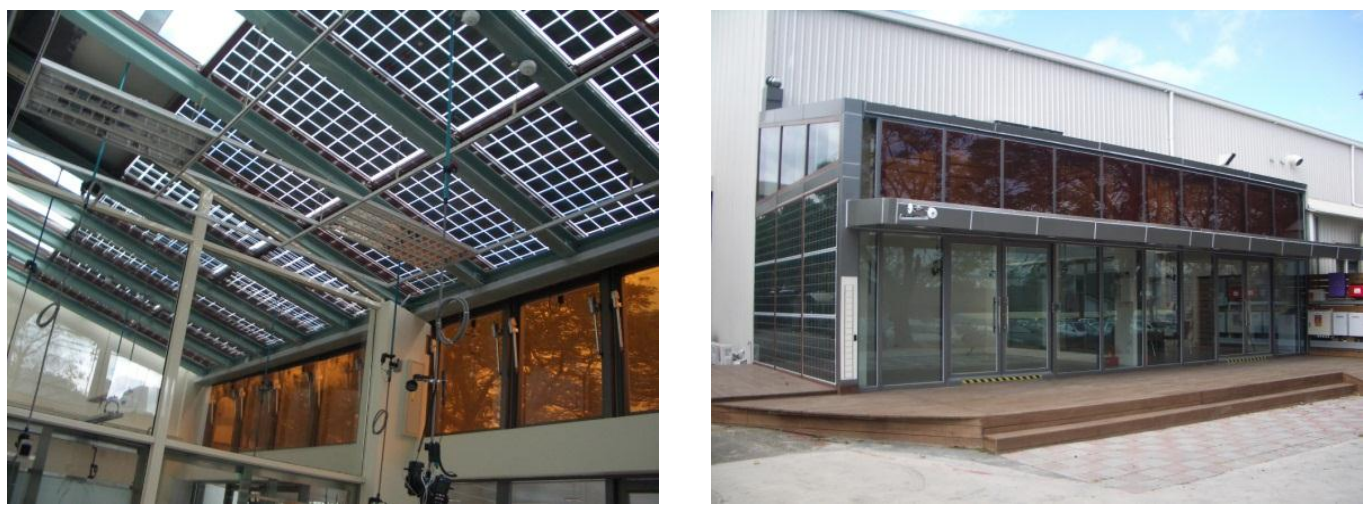

Fig. 2. Semi-transparent c-Si PV module in tiled roof has $4.2 \mathrm{~kW}$ installation capacities.

Table 1. PV module/array specification

\begin{tabular}{ll}
\hline \hline PV module & Specification \\
\hline Type & Poly-crystalline Si \\
Module efficiency $\left(\eta_{p v}\right)$ & $11.95 \%$ \\
Maximum power $\left(P_{\max }\right)$ & $210 \mathrm{~W}$ \\
Maximum power $\operatorname{voltage}\left(V_{m p}\right)$ & $28.84 \mathrm{~V}$ \\
Maximum power current $\left(I_{m p}\right)$ & $7.33 \mathrm{~A}$ \\
Open circuit voltage $\left(V_{o c}\right)$ & $36.73 \mathrm{~V}$ \\
Short circuit current $\left(I_{s c}\right)$ & $7.71 \mathrm{~A}$ \\
Temperature coefficient of $p_{\max }(\beta)$ & $-0.42 \% /^{\circ} \mathrm{C}$ \\
Module area $\left(A_{p v}\right)$ & $1.88 \mathrm{~m}^{2}$ \\
Number of Modules & 20 \\
Array area $\left(\mathrm{A}_{\mathrm{pvs}}\right)$ & $37.6 \mathrm{~m}^{2}$ \\
\hline \hline
\end{tabular}

In this paper, energy yields are important to calculate and compare. The monthly RMSE is separated calculation by monthly energy yields.

The simulated tiled solar radiation is followed the trend of the measured data quite well in the Fig. 3 . In Fig. 3, the results in the period from May to August shows that the measured and simulated tiled solar radiation can be found relatively in high accuracy. The prediction models and PVSYST5.42 models are similarly close to meet the measure data. The above result exploits a fact, that our tiled solar radiation forecasting techniques has well accuracy. More detailed data shown in Table 2 for experimental results.

Table 2. Comparison of different prediction model in tiled solar radiation results in Jan.-Dec. 2011

\begin{tabular}{llllll}
\hline \hline Month & Measurement & Prediction & Prediction Error (\%) & PVSYST 5.42 & PVSYST 5.42 Error (\%) \\
\hline Jan. & 50.7 & 46.6 & -8.0 & 46.2 & -8.8 \\
Feb. & 69.1 & 64.0 & -7.4 & 64.2 & -7.1 \\
Mar. & 61.6 & 58.8 & -4.6 & 56.7 & -8.0 \\
Apr. & 111.8 & 104.0 & -7.0 & 103.0 & -7.9 \\
May & 100.7 & 94.8 & -5.9 & 92.4 & -8.2 \\
Jun. & 138.9 & 129.8 & -6.5 & 129.3 & -6.9 \\
Jul. & 142.6 & 133.0 & -6.7 & 131.2 & -8.0 \\
Aug. & 143.3 & 133.9 & -6.6 & 131.3 & -8.4 \\
Sep. & 135.4 & 125.5 & -7.3 & 123.2 & -9.0 \\
Oct. & 112.2 & 103.3 & -7.9 & 104.6 & -6.7 \\
Nov. & 74.9 & 69.1 & -7.7 & 69.6 & -7.1 \\
Dec. & 62.6 & 57.6 & -7.9 & 57.0 & -8.9 \\
RMSE $(\%)$ & & & -6.9 & & -7.9 \\
\hline \hline
\end{tabular}




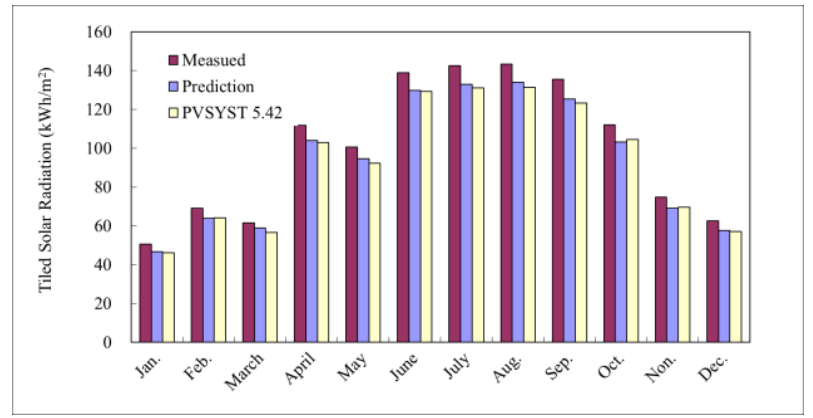

Fig. 3. Comparison results of tiled solar radiation for prediction, measured and PVSYST 5.42 from Jan. to Dec. 2011.

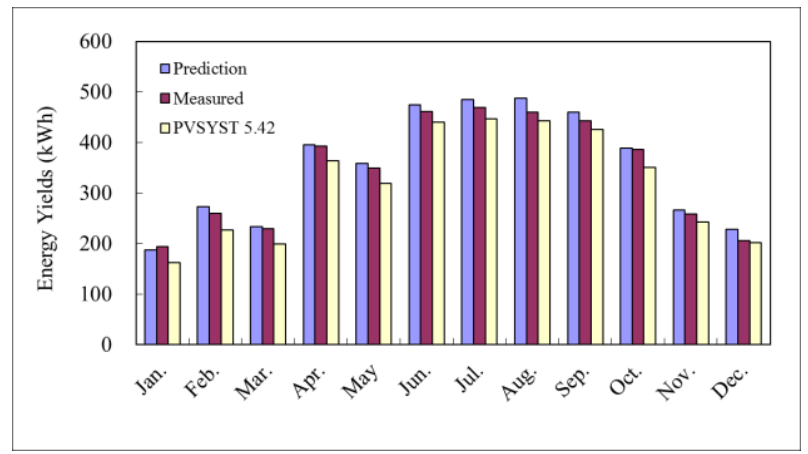

Fig. 4. Comparison results of energy yields for prediction, measured and PVSYST 5.42 from Jan. to Dec. 2011.

Table 3. Comparison of different prediction model in energy yields results in Jan.-Dec. 2011

\begin{tabular}{llllll}
\hline \hline Month & Measurement & Prediction & Prediction Error $(\%)$ & PVSYST 5.42 & PVSYST 5.42 Error (\%) \\
\hline Jan. & 194.78 & 187.33 & -3.82 & 162.70 & -16.47 \\
Feb. & 259.64 & 272.66 & 5.01 & 226.50 & -12.76 \\
Mar. & 229.61 & 234.08 & 1.95 & 199.60 & -13.07 \\
Apr. & 392.69 & 396.28 & 0.92 & 363.80 & -7.36 \\
May & 349.50 & 358.25 & 2.50 & 319.90 & -8.47 \\
Jun. & 461.88 & 474.79 & 2.80 & 439.80 & -4.78 \\
Jul. & 469.49 & 484.84 & 3.27 & 446.70 & -4.85 \\
Aug. & 460.36 & 487.45 & 5.88 & 443.30 & -3.70 \\
Sep. & 442.40 & 460.38 & 4.06 & 425.70 & -3.78 \\
Oct. & 386.59 & 388.97 & 0.62 & 351.50 & -9.08 \\
Nov. & 259.04 & 266.07 & 2.71 & 242.60 & -6.35 \\
Dec. & 206.29 & 228.34 & 10.69 & 202.60 & -1.79 \\
RMSE $(\%)$ & & & 4.92 & & 9.64 \\
\hline \hline
\end{tabular}

The simulated energy yields were followed the trend of the measured data quite well in the Fig. 4. In Fig. 4, the results in the period from April to September shows the measured and simulated energy yields can be found relatively high accuracy. The electrical energy yields with different methods in the measurement period. The prediction model and PVSYST5.42 model are similar to close the measure data. Our proposed method employs the PV derating factor that shows wiring losses, shading and aging of the panels have been considered so that more accurate than other methods. The above result exploits a fact, that our PV energy yields forecasting technique has quite well accuracy. More detailed data shown in Table 3 for experimental results.

\section{Conclusions}

Thermal model predicts the energy yields are one of the methods in the PV system. Using thermal method to predict the module temperature with local meteorological data like ambient temperature, wind speed and solar radiation is very close with measure results. The energy yields performance of the PV 
system is primarily influenced by the weather, the solar irradiance and the module temperature. This paper presents the PV system energy yields model based on thermal model method. Numerical simulation results show that our proposed approach is effective and feasible in time under the same accuracy. The statistics of time increasing the amount can improve the modeling accuracy. Our energy yields prediction results of PV system have clearly demonstrated that the RMSE performance is very well. The yearly RMSE of our prediction model is $4.92 \%$ better than PVSYS 5.42 model.

\section{Acknowledgements}

This work is supported by the Bureau of Energy, Ministry of Economic Affairs, Taiwan, R.O.C., under contract No. 102-D0305.

\section{References}

[1] Cherif H, Belhadj J. Methodology for accurate energy production estimation of photovoltaic power generation station. In: Proc. of 16th IEEE Mediterranean Electrotechnical Conference (MELECON), 2012:561-566.

[2] Huang CY, Chen HJ, Chan CC, Chou CP, Chiang CM. Thermal model based power generated prediction by using meteorological data in BIPV system. Energy Procedia, 2011; 12:531-537.

[3] Huang CJ, Huang MT, Chen CC. A novel power output model for photovoltaic system. International Journal of Smart Grid and Clean Energy, 2013; 2(3):139-147.

[4] Pratt L, King DL. The effect of uncertainty in modeling coefficients used to predict energy production using the sandia array performance model. In: Proc. of 35th IEEE Photovoltaic Specialists Conference (PVSC), 2010:002718-002723.

[5] Skoplaki E, Boudouvis AG, Palyvos JA. A simple correlation for the operating temperature of photovoltaic modules of arbitrary mounting. Solar Energy Materials \& Solar Cells, 2008; 92:1393-1402.

[6] Trinuruk P, Sorapipatana C, Chenvidhy D. Estimating operating cell temperature of BIPV modules in Thailand. Renewable Energy, 2009; 34:2515-2523.

[7] Zhou W, Yang H, Fang Z. A novel model for photovoltaic array performance prediction. Applied Energy, 2007; 84:1187-1198.

[8] Balouktsis A, Tsanakas D, Vachtsevanos G. On the optimum tilt angle of a photovoltaic array. International Journal of Sustainable Energy, 1987; 5(3): 53-169.

[9] Liu X. Calculation and analysis of optimal tilt angle for PV/T hybrid collector In: Proc. of Second International Conference on Intelligent System Design and Engineering Application, 2011:792-795.

[10] International Standard IEC 61215 Crystalline Silicon Terrestrial Photovoltaic (PV) Modules-Design Qualification and Type Approval (2005).

[11] Belfkira R, Nichita C, Barakat G. Design study and optimization of a grid independent wind/PV/diesel system. Presented at: 2009 European Conference Power Electronics and Applications. 